\title{
Visit Planning Using a Waiting Room Health IT Tool: The Aligning Patients and Providers Randomized Controlled Trial
}

Richard W. Grant, MD, MPH

Courtney Lyles, $P b D^{1,2}$

Connie S. Uratsu, RN, MS, CNS ${ }^{1}$

Michelle T. Vo, MPH

Elizabeth A. Bayliss, $M D^{3,4}$

Michele Heisler, $M D, M P A^{5,6}$

'Division of Research, Kaiser Permanente Northern California, Oakland, California

${ }^{2}$ Center for Vulnerable Populations and Division of General Internal Medicine at Zuckerberg San Francisco General Hospital, University of California San Francisco, San Francisco, California

${ }^{3}$ Institute for Health Research, Kaiser Permanente Colorado, Aurora, Colorado

${ }^{4}$ Department of Family Medicine, University of Colorado School of Medicine, Aurora, Colorado

${ }^{5}$ Center for Clinical Management Research, VA Ann Arbor Healthcare System, Ann Arbor, Michigan

${ }^{6}$ University of Michigan Department of Internal Medicine, Ann Arbor, Michigan

Conflicts of interest: authors report none.

\section{CORRESPONDING AUTHOR}

Richard W. Grant, MD, MPH

Kaiser Permanente Northern California 2000 Broadway

Oakland, CA 94612

Richard.W.Grant@kp.org

\begin{abstract}
PURPOSE Time during primary care visits is limited. We tested the hypothesis that a waiting room health information technology (IT) tool to help patients identify and voice their top visit priorities would lead to better visit interactions and improved quality of care.
\end{abstract}

METHODS We designed a waiting room tool, the Visit Planner, to guide adult patients through the process of identifying their top priorities for their visit and effectively expressing these priorities to their clinician. We tested this tool in a cluster-randomized controlled trial with usual care as the control. Eligible patients had at least 1 clinical care gap (eg, overdue for cancer screening, suboptimal chronic disease risk factor control, or medication nonadherence).

RESULTS The study (conducted March 31, 2016 through December 31, 2017) included 750 English- or Spanish-speaking patients. Compared with usual care patients, intervention patients more often reported "definitely" preparing questions for their doctor $(59.5 \%$ vs $45.1 \%, P<.001)$ and "definitely" expressing their top concerns at the beginning of the visit $(91.3 \%$ vs $83.3 \%, P=.005)$. Patients in both arms reported high levels of satisfaction with their care $(86.8 \%$ vs $89.9 \%$, $P=.20$ ). With 6 months of follow-up, prevalence of clinical care gaps was reduced by a similar amount in each study arm.

CONCLUSIONS A simple waiting room-based tool significantly improved visit communication. Patients using the Visit Planner were more prepared and more likely to begin the visit by communicating their top priorities. These changes did not, however, lead to further reduction in aggregate clinical care gaps beyond the improvements seen in the usual care arm.

Ann Fam Med 2019;17:141-149. https://doi.org/10.1370/afm.2352.

\section{INTRODUCTION}

he United States is experiencing a crisis in primary care because of the increasing complexity of our aging population and the limited time during in-person visits to accomplish all the necessary care tasks. ${ }^{1}$ A growing list of evidence-based primary care clinician responsibilities combined with unchanging (or even decreasing) visit lengths places considerable stress on the traditional primary care visit and creates barriers to productive interactions. Without new tools to improve the primary care visit interactions, millions of Americans will continue not to meet evidence-based preventive and chronic disease care goals despite the availability of effective therapies and interventions that reduce health risks and improve health. ${ }^{2}$ Optimizing care for this growing patient population is a national priority. ${ }^{2,3}$

By 2020, there will be an estimated 130 million Americans with 2 or more chronic conditions. ${ }^{4-7}$ Patients with multiple chronic conditions have more outpatient visits per year, are often prescribed complex medical regimens, generate more health care costs, experience more adverse events, and have lower health-related quality of life. ${ }^{8}$ In the time-limited 
environment of primary care, many patients may have important concerns that are not addressed. Examples of prevalent issues that are frequently unrecognized by clinicians during clinic visits include medicationrelated concerns, financial problems, and stress related to caregiving. ${ }^{9-12}$ Prior research has demonstrated that it is not simply the number of concurrent diagnoses, but the influence of behavioral, emotional, and social factors that create substantial barriers to effective clinical care. ${ }^{13,14}$ If the patient's priorities are unrecognized, as is often the case, the alignment of patient and clinician priorities and subsequent management steps cannot take place. ${ }^{15,16}$

In parallel with increasing patient complexity, there has been a substantial rise in guidelines and quality measures that primary care professionals must address at each visit. ${ }^{17,18}$ Not meeting these evidencebased metrics (eg, cancer screening, smoking cessation, chronic disease risk factor control) leads to care gaps that represent potential shortcomings in primary care. Clinicians struggle with balancing evidence and treatment decisions in complex patients. ${ }^{19} \emptyset_{\text {st- }}$ bye et $\mathrm{al}^{20}$ estimated that it would require up to 10.6 hours per day for a primary care clinician to deliver high-quality care for a typical primary care panel of patients if chronic diseases were not already under good control. Moreover, it may be clinically inappropriate to apply multiple disease-specific guidelines to a single complex patient..$^{3,21-24}$ In this setting and with limited time, clinicians must reconcile patient expectations and needs with their clinical goals for the patient.

Time constraints are a major barrier to negotiated partnerships and shared decision making between patients and clinicians. ${ }^{25-27}$ For patients with multiple competing concerns, a critical first step at a primary care visit is the decision about which issues to discuss first. Increasing patient engagement in this process is a clear example of patient-centered care, and there is a growing body of evidence linking this strategy of patient activation to improved health outcomes. ${ }^{28,29}$ Accordingly, we conducted a randomized controlled trial to evaluate the impact of a waiting room-based health information technology (IT) tool, called Visit Planner, designed to help primary care patients with at least 1 identified clinical care gap to more effectively prepare for their primary care visits. ${ }^{30}$ We tested the hypothesis that patients who were supported in identifying and communicating their visit priorities would have more effective visit interactions, which in turn would lead to more effective primary care measured as fewer evidence-based clinical care gaps compared with control peers after 6 months.

\section{METHODS}

\section{Setting and Participants}

The Aligning Patients and Providers (APP) randomized controlled trial was conducted in 8 primary care practices within Kaiser Permanente Northern California, an integrated care delivery system serving 4.2 million members in Northern California. Features of this system include use of a single electronic health record by all clinicians, and a coordinated, team-based approach to addressing quality of care.

Clinical trial participants included primary care physicians and their eligible patients. Physicians were eligible for inclusion if they had at least 5 potentially study-eligible patients within their patient panel and planned to remain at their current practice for a year. Eligible patients had at least 1 clinical care gap, based on age- and sex-specific evidence-based guidelines (Table 1); were aged 30 to 80 years ${ }_{i}$ had continuous Kaiser membership for at least 1 year ${ }_{i}$ and either had 2 or more chronic conditions or were new to their primary care physician. These patient eligibility criteria were chosen to select a trial cohort who would potentially need support in choosing from multiple different potential visit priorities. Patients were excluded if they were deemed inappropriate for participation by their physician, spoke a primary language other than English or Spanish, had visual impairment precluding their use of the Visit Planner, or had severe mental illness that would interfere with study participation.

\section{Study Design}

We conducted a 2-arm, parallel-group, clusterrandomized controlled trial with random, concealed allocation at the level of primary care physician. Enrollment of physicians began in February 2016 and was completed by February 2017. Physicians were recruited after the study was introduced during routine monthly physician meetings. The first eligible patient visit occurred on March 31, 2016, while the last visit occurred on June 30, 2017. Follow-up was assessed through December 31, 2017, that is, 6 months after the final visit. We chose a 6 -month follow-up period to balance the need to allow sufficient time for the intervention to make an impact and the need to minimize potential loss to follow-up. Both primary care physicians and patients provided informed written consent. Patients, physicians, and waiting room research assistants could not be blinded to randomization status because intervention patients were given the Visit Planner tool in the waiting room, whereas control patients were not. Collection of postvisit survey data and assembly of analytic data sets were masked to randomization status, however. The study was approved by the institutional review board of the Kaiser Foundation Research Institute. 


\section{Intervention and Control}

Intervention patients were provided the Visit Planner on a tablet tool in the waiting room. Development of the Visit Planner with user-centered design principles and involvement of stakeholders (patients, physicians, operational leaders) is described in detail elsewhere. ${ }^{30}$ The tool started off with a video that explained the purpose of the Visit Planner and educated patients about the importance of bringing up their concerns early rather than later in the visit. Then, the tool prompted them to choose their top 1 or 2 priorities for the visit from 6 categories (new problem, medicines, need something from the doctor, old problem, stress at home or at work, and a personal concern or other (Supplemental Figure 1, available at http:// www.AnnFamMed.org/content/17/2/141/suppl/DC1/). Within each category, patients had the option of choosing 3 to 4 subcategories and of inputting additional comments in a free-text field. After identifying their top visit priorities, patients were then prompted to identify how they would use their time during or after the visit to stay involved with their care (eg, take notes during the visit, ask my doctor questions during the visit, review with a friend or loved one, check online patient portal after the visit). All patient responses were subsequently printed out as a Visit Planner summary for the patient to bring into their visit. We also created a Spanish version of the tool. The process of linguistically and culturally adapting the Visit Planner is described in detail elsewhere. ${ }^{31}$

Control patients were also met in the waiting room before eligible visits and were given a 1-page healthy lifestyle education handout. Patients in both study arms otherwise received usual care throughout the clinical trial period.

\section{Study Outcomes}

Our conceptual model for the intervention effect was that the Visit Planner tool would (1) improve patient preparation and prioritization, leading to (2) more efficient and productive primary care visits that would include appropriate adjustments to the management plan, leading in turn to (3) improved quality of care over time as assessed by meeting evidence-based care guidelines. We also sought to empirically validate the premise for this model from the physician's perspective by administering a 5 -item primary care physician questionnaire at baseline during study enrollment.

Our primary patient-reported outcomes regarding their care experiences were obtained by research staff during postvisit telephone calls using questions drawn from validated survey instruments. The 27 -item questionnaire was administered within 1 week of the eligible primary care visit. We measured outcomes in the domains of patient satisfaction, autonomy, perceived involvement in care, and satisfaction with care. ${ }^{32-37}$

Our primary clinical outcome was the closing of quality care gaps defined in Table 1 within 6 months of the study visit. We chose aggregate care gaps because quality of primary care is a priority for clinical stakeholders and because this represented

Table 1. Definitions Used for Care Gaps

\begin{tabular}{|c|c|}
\hline Care Gap & Definition \\
\hline Laboratory tests overdue & Diabetes and no $\mathrm{HbA}_{1 \mathrm{c}}$ result in past 12 months \\
\hline \multirow[t]{3}{*}{$\begin{array}{l}\text { Overdue for screening } \\
\text { or treatment }\end{array}$} & $\begin{array}{l}\text { Last mammogram more than } 2 \text { years ago (for women aged } \\
50-74 \text { years) }\end{array}$ \\
\hline & $\begin{array}{l}\text { Last colorectal cancer screening more than } 1 \text { year ago (for } \\
\text { adults aged }>50 \text { years) }\end{array}$ \\
\hline & $\begin{array}{l}\text { Treatment for osteoporosis not started (for adults at high risk } \\
\text { for fracture, defined as first fracture among women aged } \\
>60 \text { years and men aged }>70 \text { years) }\end{array}$ \\
\hline \multirow[t]{4}{*}{ Not at goal } & For patients with diabetes, last $\mathrm{HbA}_{1 \mathrm{c}} \geq 8 \%$ \\
\hline & $\begin{array}{l}\text { For patients with hypertension, last } 2 \text { SBP } \geq 140 \mathrm{~mm} \mathrm{Hg} \text { or last } \\
\mathrm{SBP} \geq 150 \mathrm{~mm} \mathrm{Hg}\end{array}$ \\
\hline & $\begin{array}{l}\text { For patients with cardiovascular disease, last LDL cholesterol } \\
\text { level } \geq 160 \mathrm{mg} / \mathrm{dL}\end{array}$ \\
\hline & For patients with persistent asthma, asthma Med Ratio <0 \\
\hline \multirow{3}{*}{$\begin{array}{l}\text { Medication adherence } \\
<80 \% \text { in past year }\end{array}$} & For patients with diabetes, aged $<75$ years and last $\mathrm{HbA}_{1 \mathrm{c}} \geq 8 \%$ \\
\hline & For patients with hypertension and last 2 SBP $\geq 140 \mathrm{~mm} \mathrm{Hg}$ \\
\hline & $\begin{array}{l}\text { For patients with cardiovascular disease and last LDL cholesterol } \\
\text { level } \geq 100 \mathrm{mg} / \mathrm{dL}\end{array}$ \\
\hline Current smoker & - \\
\hline Depression monitoring & For patients with depression diagnosis, missing PHQ9 \\
\hline \multicolumn{2}{|c|}{$\begin{array}{l}\text { Asthma Med Ratio = ratio of controller to total asthma medications; } \mathrm{HbA}_{1 c}=\text { hemoglobin } \mathrm{A}_{1 c} ; \mathrm{LDL}=\mathrm{low} \text { - } \\
\text { density lipoprotein; } \mathrm{PHQ9}=9 \text {-question depression scale from the Patient Health Questionnaire; } \\
\text { SBP = systolic blood pressure. }\end{array}$} \\
\hline
\end{tabular}

a primary care-oriented outcome that was not disease specific, thereby enabling the enrollment of a more representative population of primary care patients. Individual care gaps were those monitored within our care system and were measured at baseline and 6-month follow-up as a total count of any care gap at both time periods. Change in aggregated care gaps from baseline to follow-up was assessed in 4 ways: closure of all baseline gaps, closure of any baseline gaps, opening of new care gaps, and absence of gaps at the end of the study.

\section{Statistical Methods}

We examined baseline characteristics of patients and physicians by randomization status using the $\chi^{2}$ test, the $t$ test, or nonparametric tests as appropriate. For our clinical trial 
outcomes, we constructed generalized linear mixed models (SAS Proc GLIMMIX) with the dichotomized response as a dependent variable (with a logit link), trial arm as a fixed effect, and primary care physician as a random effect to adjust for clustering of patients within physician. ${ }^{38}$ For secondary survey outcomes, the patient reports were dichotomized and analyzed in the same type of mixed models. We also conducted a priori stratified analyses of English- and Spanishspeaking patients to determine any differential effects by language. We used SAS version 9.3 (SAS Institute Inc).

\section{RESULTS}

\section{Enrollment and Participant Characteristics}

We contacted 78 primary care physicians during physician practice meetings, of whom 74 enrolled (95\% recruitment rate) with 6,006 potentially eligible patients in their patient panels. A small proportion of eligible patients were excluded by physician request (204, or 3\%). From this patient source population, we contacted 1,402 patients for our study. Among patients who scheduled an eligible visit, the study consent rate was $79 \%$ (1,110 provided informed consent, 292 declined). Participant flow in the trial is shown in Figure 1.

The average age of enrolled primary care physicians was 42.2 \pm 8.4 years and the average time in practice was $13.8 \pm 8.8$ years (Table 2). Nearly three-fourths of the physicians (71\%) were women, and approximately onethird (32\%) spoke Spanish.

Among the 750 patients who provided informed consent and completed an eligible visit during the study period, more than one-half each were women $(64.7 \%)$ and nonwhite in race/ ethnicity $(61.7 \%)$, and they had a mean age of $60.8( \pm 11.9)$ years. Approximately one-third (34.6\%) had type 2 diabetes, and patients were prescribed an average of 3 medications. Overall, the study arms were balanced by physician and participant characteristics, with the exception of Spanish-speaking patients, who were slightly more likely to be assigned to the control arm by chance.

\section{Figure 1. CONSORT flow diagram of study physicians and patients.}






\section{Physician Baseline Survey}

All physicians completed the baseline survey on enrollment that addressed elements of our premise that clinicians in our system, as elsewhere, lacked time and experienced challenges related to patient preparedness (Table 3). Almost all physicians (96\%) reported never, rarely, or sometimes having enough time during their visits. We found that fewer than one-half of physicians (49\%) reported that their patients usually or always came prepared with their top concerns, and nearly one-half $(43 \%)$ reported that patients usually or always raised concerns near the end of the visit.

\section{Patient Visit Priorities}

Among the intervention patients using the Visit Planner, the visit priorities most commonly selected were old problem $30.8 \%$ of all selections) and new problem (29.8\% of all selections). Table 4 shows the frequency of each priority (including subselections within each of the 6 main categories). Of note, one-third of these patient-selected visit priorities were related either to communication (114 of 516, 22\%, eg, needing more explanation or discussion about medications) or to mental health (68 of $517,13 \%$, eg, feeling anxious, depressed, or stressed).

\section{Patient-Reported Outcomes}

A total of 690 patients (92\% of the study cohort) completed the telephone postvisit survey after their study visit. Compared with patients in the control arm, patients allocated to the intervention arm more often reported that they definitely prepared questions for their doctor $59.5 \%$ vs $44.8 \%$ for control arm, $P<.01)$ and definitely told their doctor about their top concerns at the beginning of the visit $(91.3 \%$ vs $83.2 \%, P<.01)$ (Table 5). Patients in both arms reported very high levels of satisfaction with their care $(86.8 \%$ and $89.9 \%$ definitely satisfied, $P=.20$ ).

In contrast, autonomy and involve- ment in care planning were generally rated lower, but also with no differences observed between arms.

When stratifying by language, we found that English-speaking patients in the intervention arm were also more likely than control arm counterparts to report that they definitely prepared a list of questions for their doctor $(60.3 \%$ vs $47.7 \%, P<.01)$. For Spanish-speaking patients, however, the absolute
Table 2. Physician and Patient Characteristics

\begin{tabular}{|c|c|c|c|c|}
\hline \multirow[b]{2}{*}{ Characteristic } & \multirow[b]{2}{*}{$\begin{array}{l}\text { All Physicians } \\
\quad(\mathrm{N}=73)\end{array}$} & \multicolumn{3}{|c|}{ Group } \\
\hline & & $\begin{array}{l}\text { Intervention } \\
\text { Physicians } \\
(\mathrm{n}=37)\end{array}$ & $\begin{array}{l}\text { Control } \\
\text { Physicians } \\
(n=36)\end{array}$ & $\begin{array}{c}P \\
\text { Value }\end{array}$ \\
\hline \multicolumn{5}{|l|}{ Physicians } \\
\hline Age, mean (SD), y & $42.2(8.4)$ & $40.8(7.7)$ & $43.7(8.9)$ & .14 \\
\hline Time in practice, mean (SD), y & $13.8(8.8)$ & $12.4(8.1)$ & $15.1(9.4)$ & .19 \\
\hline Women, No. (\%) & $52(71.2)$ & $25(67.6)$ & $27(75.0)$ & .48 \\
\hline Spanish speaking, No. (\%) & $23(31.5)$ & $10(27.0)$ & $13(36.1)$ & .40 \\
\hline & & \multicolumn{3}{|c|}{ Group } \\
\hline Characteristic & $\begin{array}{l}\text { All Patients } \\
(\mathrm{N}=750)\end{array}$ & $\begin{array}{c}\text { Intervention } \\
\text { Patients } \\
(\mathrm{n}=359)\end{array}$ & $\begin{array}{l}\text { Control } \\
\text { Patients } \\
(n=391)\end{array}$ & $\begin{array}{c}P \\
\text { Value }\end{array}$ \\
\hline \multicolumn{5}{|l|}{ Patients } \\
\hline Women, No. (\%) & $486(64.8)$ & $235(64.2)$ & $251(64.2)$ & .72 \\
\hline Race/ethnicity, No. (\%) & & & & .06 \\
\hline African American & $212(28.3)$ & $115(32.0)$ & $97(24.8)$ & \\
\hline Asian & $54(7.2)$ & $20(5.6)$ & $34(8.7)$ & \\
\hline Hispanic & $167(22.3)$ & $69(19.2)$ & $98(25.1)$ & \\
\hline Other ${ }^{\mathrm{a}}$ & $29(3.9)$ & $14(3.9)$ & $15(3.8)$ & \\
\hline White & $288(38.4)$ & $141(39.3)$ & $147(37.6)$ & \\
\hline Age, mean (SD), y & $60.8(11.9)$ & $60.5(12.2)$ & $60.3(12.1)$ & .82 \\
\hline $\begin{array}{l}\text { New to primary care physi- } \\
\text { cian, No. }(\%)\end{array}$ & $200(26.7)$ & $102(28.4)$ & $98(25.1)$ & .30 \\
\hline $\begin{array}{l}\text { Spanish as primary language, } \\
\text { No. (\%) }\end{array}$ & $123(16.4)$ & $46(12.8)$ & $77(19.7)$ & .01 \\
\hline Medication count, mean (SD) & $2.8(2.7)$ & $2.8(2.7)$ & $2.6(2.6)$ & .26 \\
\hline Diabetes, No. (\%) & $259(34.5)$ & $113(31.5)$ & $146(37.3)$ & .09 \\
\hline
\end{tabular}

Table 3. Primary Care Physician Baseline Survey Responses

\begin{tabular}{|c|c|c|c|c|}
\hline \multirow[b]{3}{*}{ How often do you: } & \multicolumn{4}{|c|}{$\begin{array}{l}\text { Physicians Answering } \\
\text { "Usually" or "Always," \% }\end{array}$} \\
\hline & \multirow[b]{2}{*}{$\begin{array}{c}\text { All } \\
(\mathrm{N}=73)\end{array}$} & \multicolumn{3}{|c|}{ Group } \\
\hline & & $\begin{array}{l}\text { Intervention } \\
(\mathrm{n}=37)\end{array}$ & $\begin{array}{l}\text { Control } \\
(\mathrm{n}=36)\end{array}$ & $\begin{array}{c}P \\
\text { Value }\end{array}$ \\
\hline Elicit patients' top concerns? & 80.8 & 83.8 & 77.8 & .52 \\
\hline $\begin{array}{l}\text { Get through all the items on your } \\
\text { agenda? }\end{array}$ & 61.6 & 64.9 & 58.3 & .57 \\
\hline $\begin{array}{l}\text { Find that patients typically prepared } \\
\text { with } 1 \text { or } 2 \text { topics? }\end{array}$ & 49.3 & 40.5 & 58.3 & .13 \\
\hline $\begin{array}{l}\text { Find that patients raise concerns near } \\
\text { the end of the visit? }\end{array}$ & 43.1 & 44.4 & 41.7 & .81 \\
\hline Have enough time during your visits? & 4.1 & 4.1 & 0 & .24 \\
\hline
\end{tabular}


difference between intervention and control arms was even greater $(55.8 \%$ vs $34.3 \%$, $P=.04$ ). In contrast, although English-speaking intervention patients were still more likely than control peers to definitely tell their doctors their top concerns at the beginning of the visit $(91.7 \%$ vs $82.1 \%, P<.01)$, this difference was not observed among Spanish-speaking patients (90.7\% vs $90.0 \%, P=.89$ ).

\section{Clinical Care Gaps}

The most prevalent baseline clinical care gaps were smoking $(21.6 \%)$, high systolic blood pressure $(20.8 \%)$, high hemoglobin $\mathrm{A}_{1 \mathrm{c}}$ level (18.5\%), and high low-density lipoprotein cholesterol level (17.9\%). Baseline care gap prevalence was similar between study arms. Overall, one-half of all study patients (53\%) had all their baseline care gaps closed by the end of the 6-month follow-up period, while more than one-half ( $63 \%$ ) had at least 1 baseline care gap closed (Table 6). Only about one-fifth of patients (22\%) experienced opening of new care gaps. By the end of follow-up, $41 \%$ of patients had no open baseline or new care gaps. There were no significant differences between study arms assessed by these 4 aggregate care gap outcome measures.

\section{DISCUSSION}

Primary care is in a state of crisis due in part to the increasing complexity and decreasing time allotted to primary care visits. We conducted a patient-centered, stakeholder-informed study to evaluate a strategy of preparing patients for primary care visits using a waiting room health IT tool. The Visit Planner guided patients through a process to identify their top visit concerns and then raise these concerns at the beginning of their visit-2 visit-related behaviors deemed helpful yet uncommon by primary care physicians.

Using postvisit validated questionnaires, we found that patients using the Visit Planner reported significantly greater visit preparation and discussion of their priorities during their visit relative to control counterparts, indicating that our intervention was successful in achieving the first step in our proposed pathway toward better quality of care. These results advance our current understanding of primary care visit interactions by proving that a fairly simple, patientcentered health IT tool can improve key components of effective patient-physician communication during time-limited visits.

We found that the Visit Planner tool did not have a significant impact on our primary clinical outcome of closing care gaps, as both groups had improvement in the quality measures over time. Patient-perceived quality of care was generally rated very high and also did not differ between study arms. This finding suggests a ceiling effect limiting our ability to improve overall processes of care. Kaiser Permanente Northern California is an integrated health care system that uses a proactive, team-based approach to identify and close clinical care gaps. In this system, frequent communication and regular outreach by multiple care team members (eg, primary care physicians, medical assistants, population management nurses, and pharmacists) outside of the traditional visit tend to mitigate many of the visit-based barriers that patients and physicians may 


\section{Table 5. Patient Postvisit Survey Results}

\begin{tabular}{|c|c|c|c|c|}
\hline \multirow[b]{2}{*}{ Question } & \multicolumn{3}{|c|}{$\begin{array}{l}\text { Patients Answering } \\
\text { "Yes, Definitely," No. (\%) }\end{array}$} & \multirow[b]{2}{*}{$\begin{array}{l}\text { Odds Ratio } \\
(95 \% \mathrm{Cl})\end{array}$} \\
\hline & $\begin{array}{l}\text { Intervention } \\
(n=333)\end{array}$ & $\begin{array}{c}\text { Control } \\
(n=357)\end{array}$ & $\begin{array}{c}P \\
\text { Value }\end{array}$ & \\
\hline \multicolumn{5}{|l|}{ Quality of communication } \\
\hline $\begin{array}{l}\text { Did you prepare a list of ques- } \\
\text { tions for your doctor? }\end{array}$ & $198(59.5)$ & $160(44.8)$ & $<.01$ & $1.81(1.33-2.45)$ \\
\hline $\begin{array}{l}\text { Did you tell your doctor about } \\
\text { your top concerns at the } \\
\text { beginning of the visit? }\end{array}$ & $304(91.3)$ & $297(83.2)$ & $<.01$ & $2.18(1.32-3.59)$ \\
\hline \multicolumn{5}{|l|}{ Patient satisfaction } \\
\hline $\begin{array}{l}\text { Were you satisfied that your } \\
\text { care was well organized? }\end{array}$ & $289(86.8)$ & 321 (89.9) & .20 & $0.74(0.46-1.18)$ \\
\hline \multicolumn{5}{|l|}{ Autonomy } \\
\hline $\begin{array}{l}\text { Were you given choices about } \\
\text { treatment to think about? }\end{array}$ & $207(62.2)$ & $214(59.9)$ & .55 & $1.10(0.81-1.49)$ \\
\hline \multicolumn{5}{|l|}{ Patient-centeredness } \\
\hline $\begin{array}{l}\text { Were you asked for your ideas } \\
\text { when a treatment plan was } \\
\text { made? }\end{array}$ & $149(44.7)$ & $160(44.8)$ & .80 & $1.05(0.70-1.58)$ \\
\hline $\begin{array}{l}\text { Were you asked to talk about } \\
\text { your goals in caring for your } \\
\text { illness? }\end{array}$ & $160(48.0)$ & $190(53.2)$ & .25 & $0.83(0.60-1.15)$ \\
\hline
\end{tabular}

Table 6. Change in Aggregated Care Gaps From Baseline to Follow-up

\begin{tabular}{|c|c|c|c|c|c|}
\hline \multirow[b]{3}{*}{$\begin{array}{l}\text { Care Gap } \\
\text { Measure }\end{array}$} & \multicolumn{4}{|c|}{$\begin{array}{l}\text { Patients Whose Physicians } \\
\text { Responded "Yes," No. (\%) }\end{array}$} & \multirow[b]{3}{*}{$\begin{array}{c}\text { Odds Ratio } \\
(95 \% \mathrm{Cl})\end{array}$} \\
\hline & \multirow[b]{2}{*}{$\begin{array}{c}\text { All } \\
(\mathrm{N}=747)\end{array}$} & \multicolumn{3}{|c|}{ Group } & \\
\hline & & $\begin{array}{l}\text { Intervention } \\
(n=359)\end{array}$ & $\begin{array}{l}\text { Control } \\
(n=388)\end{array}$ & $\begin{array}{c}P \\
\text { Value }\end{array}$ & \\
\hline $\begin{array}{l}\text { All baseline care } \\
\text { gaps closed? }\end{array}$ & $394(52.7)$ & $184(51.3)$ & $210(54.1)$ & .52 & $0.90(0.65-1.24)$ \\
\hline $\begin{array}{l}\text { Any baseline care } \\
\text { gaps closed? }\end{array}$ & $473(63.3)$ & 221 (61.6) & $252(64.9)$ & .34 & $0.87(0.64-1.17)$ \\
\hline $\begin{array}{l}\text { Any new care } \\
\text { gaps opened? }\end{array}$ & $165(22.1)$ & $81(22.6)$ & 84 (21.6) & .67 & $1.09(0.74-1.60)$ \\
\hline $\begin{array}{l}\text { No care gaps at } \\
\text { end of study? }\end{array}$ & $310(41.5)$ & $143(39.8)$ & $167(43.0)$ & .39 & $0.88(0.64-1.19)$ \\
\hline
\end{tabular}

ment. This finding suggests that although preparation and prioritization may be critical initial steps in framing the agenda for a timelimited visit, more work needs to be done to improve the collaborative process of care planning during the clinic visit itself. Future interventions aiming to optimize time-limited visit communication should therefore add tools to facilitate discussions regarding collaborative care planning. ${ }^{43,44}$

The results of our baseline physician survey strongly underscore the challenges perceived by primary care physicians, many of whom reported that their patients were often unprepared and raised their concerns near the end of the visit. These physician-reported findings, interestingly, contrast with very high levels of patient-reported satisfaction with their physicians. The insufficient time during visits reported by our study physicians underscores the challenges clinicians face in addressing patient concerns during time-limited visits. ${ }^{45}$ Our physician survey results suggest that efforts to prepare patients for their visits may represents a potential pathway to the overall goal of improving primary care. This hypothesis should be face when confronted by time limitations. Studies in other settings, however, have clearly demonstrated the link between improved patient-physician visit communication (as achieved by the Visit Planner, for example) and corresponding improvement in clinical outcomes such as medication adherence and chronic disease control. ${ }^{39-42}$ This literature suggests that our intervention may have greater clinical impact if implemented in lessintegrated care settings where the primary care visit plays a more direct role in closing clinical care gaps.

An alternative explanation for the limited impact of the Visit Planner on clinical outcomes may have to do with how the patient priority information was actually used during the visit. In contrast to the high levels of patient-perceived quality of care observed, study patients in both arms reported markedly lower levels of being asked about their own ideas and goals for treat- tested in future interventions

Several study limitations should be considered. Our population of adult primary care patients had a wide range of care needs that we captured using the framework of guideline-based care gaps. Our aggregate outcome weighed different types of gaps equally. This approach had the virtue of being patient centered rather than disease centered, but the heterogeneity of the component elements may have made it more difficult to demonstrate specific clinical impacts. Evaluating outcomes over a longer time period (to enable multiple visits per patient and more time to accrue benefits from clinical management changes) may have resulted in greater clinical impact. Similarly, more specific tailoring of the intervention to the subset of patients most in need of previsit support may have yielded more marked results. 
The Visit Planner successfully guided patients to start off their primary care visits by communicating their top care priorities, an important gap in visit interactions identified in the literature and confirmed by our physician baseline surveys. This study's success in improving this crucial first step of prioritization can be seen as a building block toward the next generation of tools that address communication barriers related to care planning with the ultimate goal of improving clinical care outcomes.

To read or post commentaries in response to this article, see it online at http://www.AnnFamMed.org/content/17/2/141.

Key words: primary care; complex patients; doctor-patient communication; health IT; priorities; practice gaps; office visits; competing demands; practice-based research

Submitted August 27, 2018; submitted, revised, December 20, 2018; accepted December 31, 2018.

Funding support: Dr Grant is funded by the National Institutes of Health (R01 HL117939, R01 DK099108, K24 DK109114) and from the Patient Centered Outcomes Research Institute (CDR-1403-11992).

\section{ClinicalTrials.gov Identifier: NCT02707146}

Supplementary materials: Available at http://www.AnnFamMed. org/content/17/2/141/suppl/DC1/.

\section{References}

1. Song Z, Chopra V, McMahon LF Jr. Addressing the primary care workforce crisis. Am J Manag Care. 2015;21(8):e452-e454.

2. Institute of Medicine. Crossing the Quality Chasm: A New Health System for the 21st Century. Washington, DC: Institute of Medicine; 2001.

3. Boyd CM, Darer J, Boult C, Fried LP, Boult L, Wu AW. Clinical practice guidelines and quality of care for older patients with multiple comorbid diseases: implications for pay for performance. JAMA. 2005;294(6):716-724.

4. Vogeli $C$, Shields $A E$, Lee TA, et al. Multiple chronic conditions: prevalence, health consequences, and implications for quality, care management, and costs. J Gen Intern Med. 2007;22(Suppl 3):391-395.

5. Wolff JL, Starfield B, Anderson G. Prevalence, expenditures, and complications of multiple chronic conditions in the elderly. Arch Intern Med. 2002;162(20):2269-2276.

6. Thorpe KE, Howard DH. The rise in spending among Medicare beneficiaries: the role of chronic disease prevalence and changes in treatment intensity. Health Aff (Millwood). 2006;25(5):w378-w388.

7. Schneider KM, O'Donnell BE, Dean D. Prevalence of multiple chronic conditions in the United States' Medicare population. Health Qual Life Outcomes. 2009;7:82.

8. Field TS, Gurwitz JH, Harrold LR, et al. Risk factors for adverse drug events among older adults in the ambulatory setting. J Am Geriatr Soc. 2004;52(8):1349-1354.

9. Lindau ST, Tang H, Gomero A, et al. Sexuality among middleaged and older adults with diagnosed and undiagnosed diabetes: a national, population-based study. Diabetes Care. 2010;33(10): 2202-2210.

10. Sudore RL, Karter AJ, Huang ES, et al. Symptom burden of adults with type 2 diabetes across the disease course: diabetes $\xi$ aging study. J Gen Intern Med. 2012;27(12):1674-1681.
11. Resnick HE, Redline S, Shahar E, et al; Sleep Heart Health Study. Diabetes and sleep disturbances: findings from the Sleep Heart Health Study. Diabetes Care. 2003;26(3):702-709.

12. Trief PM, Ploutz-Snyder R, Britton KD, Weinstock RS. The relationship between marital quality and adherence to the diabetes care regimen. Ann Behav Med. 2004;27(3):148-154.

13. Grant RW, Wexler DJ, Ashburner JM, Hong CS, Atlas SJ. Characteristics of "complex" patients with type 2 diabetes mellitus according to their primary care physicians. Arch Intern Med. 2012;172(10):821-823.

14. Morris RL, Sanders C, Kennedy AP, Rogers A. Shifting priorities in multimorbidity: a longitudinal qualitative study of patient's prioritization of multiple conditions. Chronic Illn. 2011;7(2):147-161.

15. Schillinger D, Piette J, Grumbach K, et al. Closing the loop: physician communication with diabetic patients who have low health literacy. Arch Intern Med. 2003;163(1):83-90.

16. Bodenheimer T. A 63-year-old man with multiple cardiovascular risk factors and poor adherence to treatment plans. JAMA. 2007; 298(17):2048-2055.

17. Abbo ED, Zhang Q, Zelder $M$, Huang ES. The increasing number of clinical items addressed during the time of adult primary care visits. J Gen Intern Med. 2008;23(12):2058-2065.

18. Pollak KI, Krause KM, Yarnall KS, Gradison M, Michener JL, Østbye T. Estimated time spent on preventive services by primary care physicians. BMC Health Serv Res. 2008;8:245.

19. Fried TR, Tinetti ME, lannone L. Primary care clinicians' experiences with treatment decision making for older persons with multiple conditions. Arch Intern Med. 2011;171(1):75-80.

20. Østbye T, Yarnall KS, Krause KM, Pollak KI, Gradison M, Michener $\mathrm{JL}$. Is there time for management of patients with chronic diseases in primary care? Ann Fam Med. 2005;3(3):209-214.

21. Boyd CM, Vollenweider D, Puhan MA. Informing evidence-based decision-making for patients with comorbidity: availability of necessary information in clinical trials for chronic diseases. PLoS One. 2012;7(8):e41601.

22. Tinetti ME, Bogardus ST Jr, Agostini JV. Potential pitfalls of diseasespecific guidelines for patients with multiple conditions. $N$ Engl J Med. 2004;351(27):2870-2874.

23. Huang ES, Karter AJ, Danielson KK, Warton EM, Ahmed AT. The association between the number of prescription medications and incident falls in a multi-ethnic population of adult type-2 diabetes patients: the Diabetes and Aging Study. J Gen Intern Med. 2010; 25(2):141-146.

24. Durso SC. Using clinical guidelines designed for older adults with diabetes mellitus and complex health status. JAMA. 2006;295(16): 1935-1940.

25. Gravel K, Légaré F, Graham ID. Barriers and facilitators to implementing shared decision-making in clinical practice: a systematic review of health professionals' perceptions. Implement Sci. 2006;1:16.

26. Crosson JC, Heisler M, Subramanian U, et al. Physicians' perceptions of barriers to cardiovascular disease risk factor control among patients with diabetes: results from the Translating Research Into Action for Diabetes (TRIAD) study. J Am Board Fam Med. 2010; 23(2):171-178.

27. Braddock CH III, Snyder L. The doctor will see you shortly. The ethical significance of time for the patient-physician relationship. J Gen Intern Med. 2005;20(11):1057-1062.

28. Hibbard JH, Greene J. What the evidence shows about patient activation: better health outcomes and care experiences; fewer data on costs. Health Aff (Millwood). 2013;32(2):207-214.

29. Bertakis KD, Azari R. Patient-centered care is associated with decreased health care utilization. J Am Board Fam Med. 2011;24(3): 229-239.

30. Lyles CR, Altschuler A, Chawla N, et al. User-centered design of a tablet waiting room tool for complex patients to prioritize discussion topics for primary care visits. JMIR Mhealth Uhealth. 2016;4(3):e108. 
31. Ruvalcaba D, Nagao Peck H. Lyles C, Uratsu CS, Escobar PR, Grant RW. Translating/creating a culturally responsive Spanish-language mobile app for visit preparation: case study of "trans-creation". JMIR Mhealth Uhealth. 2019 Jan 3. [Epub ahead of print].

32. Lorig K, Stewart A, Ritter P, González V, Laurent D, Lynch J. Outcome Measures for Health Education and Other Health Care Interventions. Thousand Oaks, CA: Sage Publications; 1996.

33. Glasgow RE, Wagner EH, Schaefer J, Mahoney LD, Reid RJ, Greene SM. Development and validation of the Patient Assessment of Chronic Illness Care (PACIC). Med Care. 2005;43(5):436-444.

34. Kristjansson E, Tugwell PS, Wilson AJ, et al. Development of the effective musculoskeletal consumer scale. J Rheumatol. 2007;34(6): 1392-1400.

35. Lerman CE, Brody DS, Caputo GC, Smith DG, Lazaro CG, Wolfson HG. Patients' Perceived Involvement in Care Scale: relationship to attitudes about illness and medical care. J Gen Intern Med. 1990;5(1): 29-33.

36. Dyer N, Sorra JS, Smith SA, Cleary PD, Hays RD. Psychometric properties of the Consumer Assessment of Healthcare Providers and Systems (CAHPS) Clinician and Group Adult Visit Survey. Med Care. 2012;50(Suppl):S28-S34.

37. Maly RC, Frank JC, Marshall GN, DiMatteo MR, Reuben DB. Perceived efficacy in patient-physician interactions (PEPPI): validation of an instrument in older persons. J Am Geriatr Soc. 1998;46(7):889-894.
38. Roberts C, Roberts SA. Design and analysis of clinical trials with clustering effects due to treatment. Clin Trials. 2005;2(2):152-162.

39. Greenfield S, Kaplan S, Ware JE Jr. Expanding patient involvement in care. Effects on patient outcomes. Ann Intern Med. 1985;102(4): 520-528.

40. Piette JD, Schillinger D, Potter MB, Heisler M. Dimensions of patient-provider communication and diabetes self-care in an ethnically diverse population. J Gen Intern Med. 2003;18(8):624-633.

41. Doyle C, Lennox L, Bell D. A systematic review of evidence on the links between patient experience and clinical safety and effectiveness. BMJ Open. 2013;3(1):e001570.

42. Ratanawongsa N, Karter AJ, Parker MM, et al. Communication and medication refill adherence: the Diabetes Study of Northern California. JAMA Intern Med. 2013;173(3):210-218.

43. Coulter A, Entwistle VA, Eccles A, Ryan S, Shepperd S, Perera R. Personalised care planning for adults with chronic or long-term health conditions. Cochrane Database Syst Rev. 2015;(3):CD010523.

44. Lafata JE, Morris HL, Dobie E, Heisler M, Werner RM, Dumenci L. Patient-reported use of collaborative goal setting and glycemic control among patients with diabetes. Patient Educ Couns. 2013; 92(1):94-99.

45. Katerndahl D, Parchman M, Wood R. Perceived complexity of care, perceived autonomy, and career satisfaction among primary care physicians. J Am Board Fam Med. 2009;22(1):24-33. 